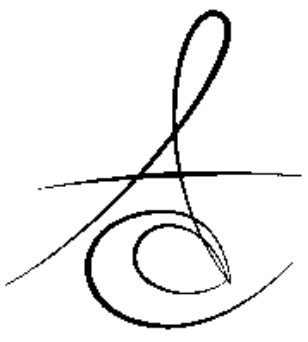

\title{
FARKLI İÇECEKLERİN POSTERİOR KOMPOZİTLERİN RENK DEĞİŞİKLİĞİ VE YÜZEY PÜRÜZLÜLÜĞÜ ÜZERİNE ETKİSİNİN DEĞERLENDİRİLMESİ
}

\section{EVALUATION OF THE DIFFERENT DRINKS EFFECT ON COLOR CHANGES AND SURFACE ROUGHNESS OF POSTERIOR COMPOSITES}

\author{
Yrd. Doç. Dr. Neslihan ÇELÍk \\ Yrd. Doç. Dr. Ömer SAĞSÖZ* \\ Yrd. Doc. Dr. Mustafa GÜNDOĞDU**
}

Makale Kodu/Article code: 2838

Makale Gönderilme tarihi: 06.05.2016

Kabul Tarihi: 29.07.2016

\section{ABSTRACT}

$\overline{\mathbf{o z}}$

Amaç: Bu çalışmanın amacı, üç farklı renklendirme solüsyonunda bekletilen posterior kompozit rezinlerin farklı periyotlarda renk değişikliği ve yüzey pürüzlülüğünün değerlendirilmesidir.

Gereç ve yöntem: Çalışma kapsamında, $2 \mathrm{~mm}$ kalınlığında ve $8 \mathrm{~mm}$ çapında disk şeklinde iki farklı posterior kompozit (X-tra fil, Quixfil) kullanılarak toplam 20 tane örnek hazırlandı. Örnekler renklendirme solüsyonlarına göre 4 gruba ayrıldı. 24 sa distile suda bekletilen örneklerin başlangıç renk ve yüzey pürüzlülük ölçümleri yapıldıktan sonra örnekler hazırlanan solüsyonlar içerisinde (kahve, kırmızı şarap, kola ve distile su) günde 3 sa bekletildi. 1 gün, 1 hafta, 15 gün ve 1 aylık renklendirme periyotları sonrasında spektrofotometre (Shade Pilot) ile renk ölçümleri tekrarlandı. En son renklendirme periyodundan sonra yüzey pürüzlülük ölçümleri profilometre (Surtronic 25) ile yapıldı. Elde edilen verilerin istatistiksel analizi tekrarlı ölçümler ANOVA, Bonferroni çoklu karşılaştırma testi ve bağımsız örneklerde t- testi kullanılarak yapıldı Bulgular: Renklendirme solüsyonlarından kırmızı şarap tüm renklendirme periyotlarında, kahve ise 1,7 ve 15 günlük renklendirme periyodunda diğer gruplara göre istatistiksel olarak anlamlı farklılık göstermiştir $(p<0,05)$. Quixfil, X-tra file göre daha fazla renklenme göstermiştir. Yüzey pürüzlülüğü değerlerinde sadece Quixfil grubunda şarap solüsyonunda bekletilen örneklerde istatistiksel olarak anlamlı farklılık tespit edilmiştir $(p=0.001)$

Sonuç: Diyetle alınan içeceğin tipi ve $\mathrm{pH}^{\prime}$ ının rezin kompozitlerin renk stabilitesi ve yüzey pürüzlülüğü üzerine etkili olduğu tespit edilmiştir.

Anahtar Kelimeler: Posterior kompozitler, renk değişimi, yüzey pürüzlülüğü
Aim: The aim of this study was to evaluate of two posterior composites color changes and surface roughness which is immersed in three different staining solutions during different time periods.

Material and Methods: In this study, 20 disc shaped samples were prepared as $2 \mathrm{~mm}$ thickness and $8 \mathrm{~mm}$ diameter from two different posterior composite (X-tra fil, Quixfil). The samples were divided into four groups according to the staining solutions. After initial color and surface roughness mesaurements of incubated samples during $24 \mathrm{~h}$ in distilled water were taken, samples immersed in prepared solutions (coffee, red wine, cola, and distilled water) during $3 \mathrm{~h}$ in a day. Color measurements were repeated with specthrophotometer (Shade Pilot) after 1 day, 1 week, 15 days and 1 month after coloring process. Surface roughness were evaluated by profilometer (Surtronic 25) after recent coloring process. The statistically analysis of obtained data were performed with use repeated measure ANOVA, Bonferroni post-hoc test and independent samples ttest.

Results: Red wine showed significant difference compared the other groups in all coloring periods, coffee showed significant difference in 1, 7 and 15 days of coloring periods $(p<0,05)$. Quixfil showed more discoloration than X-tra fil. Surface roughness of Quixfil incubated in red wine solutions had statistically significant differences $(p=0.001)$

Conclusion: Type and $\mathrm{pH}$ of dietary beverage were found to be effective on color stability and surface roughness of resin composites.

Key Words: Posterior composites, color changes, surface roughness

\footnotetext{
* Atatürk Üniversitesi, Diş Hekimliği Fak. Restoratif Diş Tedavisi Anabilim Dall, Erzurum

${ }^{* *}$ Atatürk Üniversitesi, Diş Hekimliği Fak. Protetik Diş Tedavisi Anabilim Dalı, Erzurum
} 


\section{GİRİŞ}

Amalgam ve altın alaşımlarına alternatif olarak, estetik dolgu maddelerinin posterior dişlerde uygulanması 1980 'li yıllarda posterior kompozitlerin geliştirilmesine yol açmıştır ${ }^{1}$. Diş renginde olmaları, civa içermedikleri için toksik etki göstermemeleri, iletkenliklerinin düşük olması, konservatif kavite preperasyonu için uygun olmaları ve kenar sızıntılarının daha az olması gibi olumlu özelliklerinden dolayı son dönemlerde sıklıkla tercih edilmektedir ${ }^{1,2}$. Doldurucu oranı artırılarak posterior bölgede aşırı yük alan bölgelerde amalgama benzer şekilde uygulama imkanı sağlarlar. Yüksek doldurucuların ilavesi, bu materyallerin el ile işlenmelerine ve yüksek fiziksel-mekanik özellikler göstermesine neden olmaktadır ${ }^{3}$. Yüksek yoğunluğu nedeniyle $5 \mathrm{~mm}^{\prime}$ ye kadar derin polimerizasyon sağlayarak kavitelerin tek seferde doldurulmasına imkan vermektedir. Kontak noktalarının ideale yakın oluşturulabilmesi, kaviteye basınç uygulayarak daha kolay yerleştirilebilmeleri nedeniyle Sınıf II kavitelerde başarıyla uygulanmaktadır ${ }^{4}$. Fakat hibrit kompozitlere oranla daha büyük doldurucu partiküller içermesinden dolayı, bitirme ve polisaj işlemlerinden sonra pürüzlü yüzey oluşma riski fazladır².

Kompozit rezinlerin estetik olarak başarılı olmaSı, yüzey pürüzlülüğü ve renk stabilitesi ile doğrudan ilişkilidir $^{5,6}$. Yüzey pürüzlülüğü, estetik problemlerin yanı sıra, neden olduğu plak retansiyonu, yüzey renklenmesi ve sekonder çürük oluşumu ile restorasyonun klinik ömrünüde azaltır $^{7-9}$. Kompozit rezin restorasyonların yüzey pürüzlülüğünü etkileyen faktörler; içeriğindeki monomer tipi, doldurucuların şekli ve boyutu ve polimerizasyon derinliğidir. Kompozit rezinlerde daha düzgün yüzeyler elde edebilmek amacıyla doldurucu partiküllerin boyutlarının azaltılarak doldurucu miktarının arttırıması amaçlanmaktadır ${ }^{10,11}$.

Kompozit rezinlerin renklenmesinde; amin akseleratörlerin oksidasyonu, polimer matriks yapıda oluşan oksidasyon, reaksiyona girmemiş metakrilat gruplarının varlığı ve resin matrikste suyun emilimi gibi iç kaynaklı faktörlerin yanı sıra, renklendirici ajanların absorbsiyon ve adsorbsiyonu gibi dış kaynaklı faktörler etkili olmaktadır ${ }^{12,13}$.

Renk değişikliğinin değerlendirilmesinde Munsell Renk Sistemi ve Commission Internationale de I'Eclairage (CIE) Renk Sistemi kullanılmaktadır. CIELab renk sisteminde renk üç boyutlu olarak gösterilebilmektedir. Bu renk sisteminin avantajı Munsell renk sistemine göre rengin hemen hemen eşit aralıklarda ifade edilebilmesidir. CIELab renk sisteminde $L^{*}$, $a *$ ve $b^{*}$ olmak üzere üç koordinat bulunur. $L^{*}$ rengin aydınlığını ifade eder ve $0-100$ arası bir skalada değerlendirilir. $L^{*}=0$ saf siyaha $L^{*}=100$ ise saf beyaza denk gelir. $a^{*}$ ve $b^{*}$ ise rengin tonunu ifade eder; a kırmızıdan yeşile, $b$ ise maviden sarıya renk değişimini gösterir. Bu üç koordinat rengin sayısal olarak değerini verir ve renk değişimlerinin belirlenmesinde tek bir değer $\Delta \mathrm{E}$ kullanılmasını sağlar. Bu yöntem diş hekimliğinde araştırmacılar tarafından sıklıkla kullanılmaktadır ${ }^{14,15}$.

$\mathrm{Bu}$ çalışmanın amacl, iki farklı posterior kompozit materyalinde çeşitli renklendirme solüsyonlarına değişik sürelerde maruz kaldıktan sonra oluşan renk değişikliğinin ve yüzey pürüzlülüğünün değerlendirilmesidir.

\section{MATERYAL VE METOD}

\section{Örneklerin Hazırlanması}

Bu çalışmada kullanılan 2 farklı posterior kompozit rezin materyali Tablo 1' de gösterildi. Her bir materyalden 20 adet örnek hazırlandı. Kompozitler 2 mm kalınlığında ve $8 \mathrm{~mm}$ çapında paslanmaz çelik kalıp içerisine yerleştirildikten sonra düzgün yüzey elde etmek için kompozit yüzeyine selüloid bant ve mikroskop camı yerleştirilerek üretici firmanın önerileri doğrultusunda ışık yoğunluğu $1200 \mathrm{~mW} / \mathrm{cm}^{2}$ olan ışık cihazı ile (Elipar Freelight II, 3M ESPE, St. Paul MN, ABD) polimerize edildi. Polimerizasyon cihazının ışık yoğunluğu radiometre (Hilux Ultra Plus Curing Units, Benlioğlu Dental) ile kontrol edildi. Polimerizasyondan sonra örneklerin yüzeyleri cila diskleri (Sof-Lex, 3M ESPE, St.Paul, MN, ABD) kullanılarak cilalandı ve her grupta 5 örnek olacak şekilde 4 gruba ayrıldı. Başlangıç renk ve pürüzlülük ölçümleri 24 sa distile suda bekletildikten sonra yapıldı. Ölçümler yapıldıktan sonra örnekler kahve (Nescafe Classic, Bursa, Turkey - 150 $\mathrm{mL}$ kaynayan suya 2 gr'lik 1 paket kahve karıştırılarak hazırlandı) (pH: 5,50), kırmızı şarap (DLC Öküzgözü 2009, Doluca, İstanbul, Turkey) ( $\mathrm{pH}: 3,28)$ ve kola (Coca-Cola Company, Turkey) ( $\mathrm{pH}: 2,51)$ olmak üzere üç farklı renklendirme solüsyonu içerisine konuldu. Kontrol olarak distile su ( $\mathrm{pH}: 6,47)$ kullanıldı. Kompozit rezinler renklendirme solüsyonlarında günde 3 saat bekletildi. Bu süreler dışında örnekler distile suya

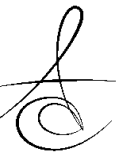


konuldu. Renklendirme solüsyonlarında 1 gün, 1 hafta, 15 gün ve 1 ay süreyle beklettikten sonra renk ölçümleri yapıldı. Yüzey pürüzlülüğü ölçümleri en son renklendirme periyodundan sonra (1 ay) yapıldı.

\section{Renk Değerlendirmesi}

Renk ölçümlerinin yapılmasında spektrofotometre (Shade Pilot, DeguDent, Hanau-Wolfgang, Almanya) cihazı kullanılarak her bir ölçüm CIE L* a* b* değeri olarak kaydedildi. Ölçümler gün ışığına karşılık gelen D65 standart aydınlatma koşullarında yapıldı ve her ölçümden önce cihaz kalibre edildi. Ölçümler standart beyaz zemin ( $L=91.2, a=-0.6, b=1.4)$ üzerinde yapıldı ve her örnekten 3 kez ölçüm yapılarak ortalama CIE L* a* b* değeri elde edildi. Kompozit örnekler arasındaki $\Delta \mathrm{E}$ değerleri aşağıdaki formül kullanılarak hesaplandı.

$$
\begin{aligned}
& \Delta \mathrm{E}=\left[(\Delta \mathrm{L})^{2}+(\Delta \mathrm{a})^{2}+(\Delta \mathrm{b})^{2}\right]^{1 / 2}, \\
& \left(\Delta \mathrm{L}=\mathrm{L} 2^{*}-\mathrm{L} 1 *, \Delta \mathrm{a}=\mathrm{a} 2^{*}-\mathrm{a} 1^{*} \text { ve } \Delta \mathrm{b}=\mathrm{b} 2 *-\mathrm{b} 1 *\right) \\
& \mathrm{L} 2, \text { a2 ve b2 değerleri, kompozit örneklerin her }
\end{aligned}
$$
bir renklendirme periyodunda ölçülen CIE L* a* b* değerlerini, L1, a1 ve b1 değerleri ise başlangıçta ölçülen CIE L* a* b* değerlerini temsil etmektedir.

\section{Yüzey Pürüzlülüğünün Değerlendirilmesi}

Renklendirme işlemi sonunda kompozit rezinlerin yüzey pürüzlülük değerleri (Ra); aralık (range): 100 $\mu \mathrm{m}$, değerlendirme uzunluğu (evaluation lenght): 1.25 $\mathrm{mm}$, kesme uzunluğu (cut- off): $0.25 \mathrm{~mm}$ olarak kalibre edilmiş Surtronic 25 profilometre cihazı (Taylor Hobson, Leicester, UK) ile ölçüldü. Yüzey pürüzlülüğünün değerlendirilmesinde her örnek yüzeyinden 3 ölçüm yapıldı. İstatistiksel analizde ortalama Ra değerleri kullanıldı.

\section{İstatistiksel Analiz}

Elde edilen verilerin istatistiksel analizi SPSS 18.0 (SPSS Inc. Chicago, IL, ABD), programı kulanılarak yapıldı. Kompozit materyallerde zamanla meydana gelen renklenme miktarlarının analizinde tekrarlı ölçümler ANOVA, farklılık olması durumunda kaynağın tesptinde Bonferroni çoklu karşılaştırma testi kullanıldı. Kompozit materyallerin farklı solüsyonlarda başlangıç ve renkleşme sonrası pürüzlülük değerleri bağımlı örneklerde $\mathrm{t}$ testi kullanılarak karşılaştırıldı. Farklı solüsyonlarda kompozit materyaller arasında renk ve pürüzlülük farkıı̆ı̆ının tespitinde bağımsız örneklerde $t$ testi uygulandı.

Tablo 1. Çalışmada kullanılan kompozit materyallerin içerikleri

\begin{tabular}{|c|c|c|c|c|c|}
\hline Materyal & Solüsyon & 1 gün & 7 gün & 15 gün & 30 gün \\
\hline \multirow[t]{4}{*}{ X-tra fil } & Distile Su & $0.72 \pm 0.47$ & $1.19 \pm 0.30$ & $1.19 \pm 0.38$ & $1.45 \pm 0.33$ \\
\hline & Kahve & $1.21 \pm 0.27$ & $4.13 * \pm 0.60$ & $5.45 * \pm 0.22$ & $6.91 * \pm 0.56$ \\
\hline & Kola & $0.86 \pm 0.12$ & $1.68 \pm 0.16$ & $2.22 \pm 0.25$ & $2.83 \pm 0.30$ \\
\hline & K. Şarap & $3.01 \pm 0.52$ & $7.59 * \pm 0.47$ & $11.02 * \pm 0.31$ & $14.21 * \pm 0.28$ \\
\hline \multirow[t]{4}{*}{ Quixfil } & Distile Su & $1.37 \pm 0.53$ & $0.89 \pm 0.24$ & $1.22 \pm 0.54$ & $0.63 \pm 0.27$ \\
\hline & Kahve & $1.61 \pm 0.61$ & $4.28 * \pm 0.56$ & $6.17 * \pm 0.92$ & $6.74 * \pm 0.66$ \\
\hline & Kola & $3.19 \pm 0.58$ & $5.48 * \pm 1.90$ & $6.28 * \pm 2.87$ & $3.51 * \pm 0.75$ \\
\hline & K. Şarap & $5.36 * \pm 0.67$ & $10.78 * \pm 0.34$ & $13.31 * \pm 0.41$ & $15.49 * \pm 0.52$ \\
\hline
\end{tabular}

\begin{tabular}{|c|l|l|c|c|}
\hline & \multicolumn{1}{|c|}{ Matriks } & Doldurucu & Ağırlık(\%) & $\begin{array}{c}\text { LOT } \\
\text { Numarası }\end{array}$ \\
\hline $\begin{array}{c}\text { X-tra fil } \\
\text { (micro-hybrid/ } \\
\text { hybrid) }\end{array}$ & $\begin{array}{l}\text { Bis-GMA, UDMA, } \\
\text { TEGDMA }\end{array}$ & $\begin{array}{l}\text { Barium-boron-alumino- } \\
\text { silicate glass }(2-3 \mu \mathrm{m})\end{array}$ & 86 & 1039408 \\
\hline $\begin{array}{c}\text { Quixfil } \\
\text { (micro-hybrid/ } \\
\text { hybrid) }\end{array}$ & $\begin{array}{l}\text { Bis-EMA, UDMA, } \\
\text { TEGDMA, }\end{array}$ & $\begin{array}{l}\text { Strontium-alumino- } \\
\text { sodium-fluoro-phosphate- } \\
\text { silicate glass }(0.1-4 ; 5- \\
50 \mu \mathrm{m})\end{array}$ & 85.5 & $\begin{array}{c}\text { Voco GmbH, } \\
\text { Cuxhaven, } \\
\text { Germany }\end{array}$ \\
DMTMA & $\begin{array}{c}\text { Dentsply, } \\
\text { Konstanz, } \\
\text { Germany }\end{array}$ \\
\hline
\end{tabular}

Tablo 2. Renklenme Sonrası Ortalama $\Delta \mathrm{E}$ ve Standart Sapma Değerleri

*Klinik olarak kabul edilemez renk değişimini göstermektedir $(\Delta \mathrm{E} \geq 3,3)$ 


\section{BULGULAR}

Gruplar için ortalama $\Delta \mathrm{E}$ değerleri ve standart sapmaları Tablo 2 de gösterilmiştir. Renk değişiminin analizinde klinik olarak kabul edilebilir sınır $\Delta \mathrm{E}=3.3$ olarak belirlenmiştir. 24 sa' lik renklendirme sonrası sadece kırmızı şarapta bekletilen Quixfil grubundaki renk değişimi klinik olarak kabul edilemez seviyededir $(\Delta \mathrm{E}=5.36) .7,15$ ve 30 günlük renklendirme periyotlarında kahve ve kırmızı şarap her iki kompozit materyalinde renklenmeye sebep olmuştur $(\Delta \mathrm{E}>3.3)$. Kola 7,15 ve 30 günlük renklendirme periyotlarında sadece
Quixfil grubunda klinik olarak kabul edilemeyen renklenmeye sebep olmuştur ( $\Delta \mathrm{E}>3.3)$. Quixfil, X-tra file göre daha fazla renklenme göstermiştir. Renklendirme solüsyonlarından kırmızı şarap tüm renklendirme periyotlarında kahve ise 1,7 ve 15 günlük renklendirme periyodunda diğer gruplara göre istatistiksel olarak anlamlı farklılık göstermiştir. ( $p<0,05$, Tablo 4). Yüzey pürüzlülüğü değerlerinde sadece Quixfil grubunda şarap solüsyonunda bekletilen örneklerde istatistiksel olarak anlamlı farklılık tespit edilmiştir ( $p=0.001$, Tablo 5$)$. Solüsyonlar içerisinde sadece kırmızı şarap grubunda yüzey pürüzlülüğü deăerlerinde anlamlı farklılık vardır ( $\mathrm{D}=0.001$. Tablo 6)

Tablo3. Kompozit materyallerde zamanla meydana gelen renklenme miktarlarına ait istatistiksel karşılaştırma sonuçları

\begin{tabular}{|l|l|l|l|l|l|}
\hline Materyal & Solüsyon & $\mathbf{1}$ gün & $\mathbf{7}$ gün & $\mathbf{1 5}$ gün \\
\hline \multirow{2}{*}{ X-tra fil } & & & & \\
& Distile Su & $0.72 \pm 0.47 a$ & $1.19 \pm 0.30 \mathrm{a}$ & $1.19 \pm 0.38 \mathrm{a}$ \\
\cline { 2 - 6 } & Kahve & $1.21 \pm 0.27 \mathrm{a}$ & $4.13 \pm 0.60 \mathrm{~b}$ & $5.45 \pm 0.22 \mathrm{c}$ & $6.91 \pm 0.33 \mathrm{a}$ \\
\cline { 2 - 6 } & Kola & $0.86 \pm 0.12 \mathrm{a}$ & $1.68 \pm 0.16 \mathrm{a}$ & $2.22 \pm 0.25 \mathrm{~b}$ & $2.83 \pm 0.30 \mathrm{~b}$ \\
\cline { 2 - 6 } & K. Şarap & $3.01 \pm 0.52 \mathrm{~b}$ & $7.59 \pm 0.47 \mathrm{c}$ & $11.02 \pm 0.31 \mathrm{~d}$ & $14.21 \pm 0.28 \mathrm{~d}$ \\
\hline \multirow{2}{*}{ Quixfil } & Distile Su & $1.37 \pm 0.53 \mathrm{a}$ & $0.89 \pm 0.24 \mathrm{a}$ & $1.22 \pm 0.54 \mathrm{a}$ & $0.63 \pm 0.27 \mathrm{a}$ \\
\cline { 2 - 6 } & Kahve & $1.61 \pm 0.61 \mathrm{a}$ & $4.28 \pm 0.56 \mathrm{~b}$ & $6.17 \pm 0.92 \mathrm{~b}$ & $6.74 \pm 0.66 \mathrm{c}$ \\
\cline { 2 - 5 } & Kola & $3.19 \pm 0.58 \mathrm{~b}$ & $5.48 \pm 1.90 \mathrm{~b}$ & $6.28 \pm 2.87 \mathrm{~b}$ & $3.51 \pm 0.75 \mathrm{~b}$ \\
\cline { 2 - 5 } & K.Şarap & $5.36 \pm 0.67 \mathrm{c}$ & $10.78 \pm 0.34 \mathrm{c}$ & $13.31 \pm 0.41 \mathrm{c}$ & $15.49 \pm 0.52 \mathrm{~d}$ \\
\hline
\end{tabular}

Aynı sütundaki farklı harfler istatistiksel olarak anlamlıdır $(p<0,05)$.

Tablo 4. Farklı solüsyonlarda kompozit materyallerde zamanla meydana gelen renklenme miktarlarına ait istatistiksel karşılaştırma sonuçları (Independent $t$ test)

\begin{tabular}{|c|c|c|c|c|c|c|c|c|}
\hline \multirow[t]{2}{*}{ Solüsyon } & \multicolumn{2}{|c|}{1 gün } & \multicolumn{2}{|c|}{7 gün } & \multicolumn{2}{|c|}{15 gün } & \multicolumn{2}{|c|}{30 gün } \\
\hline & $\mathbf{t}$ & p & $t$ & $\mathbf{p}$ & $\mathbf{t}$ & $\mathbf{p}$ & $\mathbf{t}$ & p \\
\hline Distile Su & $-2,044$ & ,075 & 1,735 & 121 &,- 094 & ,927 & 4,207 & ,003* \\
\hline Kahve & $-1,325$ & 222 &,- 430 & 678 & $-1,712$ & 125 &, 431 & 678 \\
\hline Kola & $-8,832$ & ,000* & $-4,460$ & ,002* & $-3,148$ & ,014* & $-1,871$ & ,098 \\
\hline K.Sarap & $-6,213$ & $000 *$ & $-12,286$ & $000 *$ & $-9,888$ & $000 *$ & $-4,811$ & $001^{*}$ \\
\hline
\end{tabular}

$* p<0,05$

Tablo 5. Kompozit materyallerin farklı solüsyonlarda başlangıç ve renklenme sonrası ortalama pürüzlülük değerleri ve istatistiksel olarak karşılaştırma sonuçları (Paired t test)

\begin{tabular}{|c|c|c|c|c|c|}
\hline Materyal & Solüsyonlar & & Ortalama \pm SS & $\mathbf{t}$ & $\mathbf{p}$ \\
\hline & & Renklenme Sonrası & $0,37 \pm 0,28$ & & \\
\hline \multirow[t]{6}{*}{ X-tra fil } & & Renklenme Sonrası & $0,46 \pm 0,40$ & & \\
\hline & Kola & Başlangıç & $0,35 \pm 0,34$ & 0,425 & 0,693 \\
\hline & & Renklenme Sonrası & $0,26 \pm 0,28$ & & \\
\hline & Distile Su & Başlangıç & $0,60 \pm 0,53$ & 1,572 & 0,191 \\
\hline & & Renklenme Sonrası & $0,19 \pm 0,09$ & & \\
\hline & Kahve & Başlangıç & $0,25 \pm 0,13$ & $-0,692$ & 0,527 \\
\hline \multirow[t]{3}{*}{ Quixfil } & & Renklenme Sonrası & $0,34 \pm 0,29$ & & \\
\hline & Kola & Başlangıç & $0,30 \pm 0,26$ & $-1,923$ & 0,127 \\
\hline & & Renklenme Sonrası & $0,48 \pm 0,09$ & & \\
\hline
\end{tabular}


Tablo 6. Farklı solüsyonlarda kompozit materyallerin başlangıç ve renklenme sonrası pürüzlülük değerlerine ait istatistiksel karşılaştırma sonuçları (Independent t test)

\begin{tabular}{|l|l|c|c|}
\hline \multicolumn{1}{|c|}{ Solüsyonlar } & & t & p \\
\hline Distile Su & Başlangıç & $-1,432$ & 0,190 \\
\hline & Renklenme Sonrası & 1,352 & 0,213 \\
\hline Kahve & Başlangıç & 0,837 & 0,427 \\
\hline & Renklenme Sonrası & 0,845 & 0,599 \\
\hline Kola & Başlangıç & 0,252 & 0,807 \\
\hline & Renklenme Sonrası & $-1,641$ & 0,140 \\
\hline Kırmızı Şarap & Başlangıç & $-2,064$ & 0,073 \\
\hline \multicolumn{3}{|l|}{} \\
*p $<0,05$ & Renklenme Sonrası & $-5,406$ & $0,001^{*}$ \\
\hline
\end{tabular}

\section{TARTIŞMA}

Materyallerin yapısal farklılıları, oral kavitedeki dinamik değişiklikler, yiyecek ve içeceklerdeki renklendirici ajanlar ve ph değişiklikleri bu materyallerin özelliklerini etkileyebilmektedir. Bu çalışmada da farklı içeceklerin posterior kompozitlerin renk stabiliteleri ve yüzey pürüzlülüğüne olan etkileri değerlendirilmiştir.

Diş hekimliği alanında CIE L*a*b* renk sistemi, $\Delta \mathrm{E}$ değerinin tespiti için birçok araştırmada tercih edilmekte ve literatürde en sık kullanılan renk ölçüm sistemi olarak ifade edilmektedir ${ }^{16}$. Renk farklılıklarının algılanmasında insan gözü sınırlı kapasiteye sahiptir. İdeal izleme şartları sağlandığında $\Delta \mathrm{E}$ değerinin 2.0' den büyük olduğu durumlarda gözlemcilerin büyük bir kısmı renk değişikliğini kolaylıkla algılayabilmişlerdir. Ancak $\Delta \mathrm{E}$ değerinin 1.0' in altında olduğu durumlarda ise renk değişikliklerinin izlenemediği bildirilmiştir ${ }^{17}$. Yapılan çalışmalarda klinik koşullar altında insan gözünün 3.3 ve bundan büyük $\Delta \mathrm{E}$ değerlerini fark edebileceği rapor edilmişitir ${ }^{16,17}$. Renk değişikliğinin tespitinde potansiyel hataları en aza indirmek, çıplak gözle tespit edilemeyen renk değişikliklerini belirlemek ve objektif ölçüm yapabilmek için dijital renk ölçüm cihazları geliştirilmiştir ${ }^{18}$. Bu çalışmada da $\Delta \mathrm{E}$ değerlerinin tespitinde spektrofotometre kullanılmıştır.

Restoratif materyaller üzerinde bakteri kolonizasyonu, yüzey pürüzlülüğü ile doğrudan ilişki göstermektedir $^{19}$. Restoratif materyallerin yüzey pürüzlülüklerinin değerlendirilmesinde genellikle in vitro yöntemler tercih edilmekte ve yaygın olarak profilometre cihazı kullanılmaktadır. Profilometre, yüzey pürüzlülüğünü mikron seviyesinde ölçebilen, materyallerden elde edilmiş olan test örneklerinin yüzey topografisindeki değişikliklerin kalitatif değerlendirilmesinde kullanılan bir cihazdır ${ }^{20}$. Ortalama yüzey pürüzlülüğü için kritik değer $0.2 \mu \mathrm{m}^{\prime} \operatorname{dir}^{19}$. Bu değerin üzerinde bakteri kolonizasyonunun arttığı bilinmektedir. Çalışmamızda yüzey pürüzlülüğünü analizinde profilometre cihazı kullanılmıştır.

Rezin kompozitin yapısı ve partiküllerin boyutu yüzey pürüzlülüğü üzerinde direk etkiye sahiptir ve materyallerin dış kaynaklı renklenmesine sebep olabilir. Materyalin içeriğinin yanı sıra yüzey bitirme ve cila işlemleri de kompozitin yüzey yapısını ve erken renklenmesini etkileyebilir ${ }^{18,21}$. Bu çalışmada, örneklerin yüzey düzgünlüğünü sağlamak için, bitirme işlemleri standart cila diskleriyle sırasıyla uygulanmıştır. Kompozit rezinlerin renk stabilitesi ve yüzey pürüzlülüğünü; saklama solüsyonlarının $\mathrm{pH}^{\prime}$ । ve kişinin diyet ve oral alışkanlıklarının etkilediği yapılan çalışmalarda ifade edilmiştir ${ }^{22,23}$.

Ertaş ve arkadaşları ${ }^{24}$ yaptıkları çalışmada, 5 farklı kompozit rezinin kolada, suda, çayda, kahvede ve kırmızı şarapta oluşan renk değişimini kolorimetre ile değerlendirmişlerdir. Su içerisinde bekletilen kompozitlerde daha az renk değişimi görülürken, kırmızı şarap içerisinde bekletilen örneklerde daha fazla renk değişimi olduğunu tespit etmişlerdir. Fujita ve arkadaşları ${ }^{25}$ bir akıcı kompozit ve bir hibrit kompozit rezinin kahve, yeşil çay ve kırmızı şaraptaki renk değişikliklerini inceledikleri çalışmalarında en fazla renk değişiminin 21 gün sonra kırmızı şarapta meydana geldiğini bildirmişlerdir. Çaydaki renklendirici ajanların sadece yüzeye absorbe olduğu, kahvedekilerin ise hem absorbsiyon hem de adsorbsiyonla renk değişimi oluşturduğu bildirilmiş̧irir ${ }^{26}$ Um ve Ruyter ${ }^{27}$ kahvedeki renklendiricilerin yüzeye yapıştıktan sonra sabit kalıp, çaydakilerin ise uzaklaşıı̆ını bundan dolayı kahvenin daha fazla renk değişikliğine sebep olduğunu belirtmişlerdir. Yapılan çalışmalara benzer şekilde bizim çalışmamızda da X-tra fil ve Quixfil grubunda en fazla renk değişimi kahve ve kırmızı şarapta bekletilen örneklerde görülmüştür.

Asidik karakterdeki içeceklerin kompozit rezinlerin yüzeylerinde bozulmaya sebep olarak materyallerin yüzey pürüzlülüğünün artırdığı bildirilmiştir ${ }^{28}$. Kullanılan içecekler içerisinde kırmızı şarap $(\mathrm{pH}: 3,28)$ her iki materyalde yüzey pürüzlülüğünün artı̧̧ına sebep olmuştur. Değerlendirilen içeceklerin $\mathrm{pH}^{\prime}$ । sonuçları etkilemiştir. Ancak kola en düşük $\mathrm{pH}^{\prime}$ a sahip olmasına rağmen en fazla yüzey pürüzlülüğü şarapta bekletilen örneklerde görülmüştür. Yapılan klinik çalışmalarda içeceklerin eroziv potansiyelinin sadece $\mathrm{pH}^{\prime}$ a

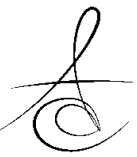


değil aynı zamanda mineral içeriği ve tamponlama kapasitesine bağlı olarak değiştiği tespit edilmiştir ${ }^{29,30}$. Çalışmamızda kırmızı şarapta renk değişiminin fazla olması, alkolün etkisiyle kompozit rezinlerin yüzey pürüzlülüğünün artması ve boyayıcı pigmentlerin adsorbsiyonuna bağlı olarak oluştuğunu düşündürmektedir.

Yapar ve Gül ${ }^{31}$ yaptıkları çalışmalarında kompozit rezinlerin içinde bulunan BisGMA (Bisfenol-A glisidildimetakrilat), UDMA (Üretan dimetakrilat) ve TEGDMA gibi çeşitli monomerler ile farklı tip ve boyuttaki doldurucu partiküllerin kompozitte renk değişimine sebep olduğunu bildirmişlerdir. Renk değişimine karşı UDMA'nın BisGMA'dan daha dirençli olduğu, normal polimerizasyon şartlarında UDMA' nın BisGMA' dan daha az su emilmi gösterdiği belirlenmiştir ${ }^{32}$. Bagheri ve arkadaşları $^{13}$ TEGDMA içeren rezin kompozitlerin UDMA içeren kompozitlerden daha fazla renk değişimine eğilimli olduğunu belirtmişlerdir. İnorganik doldurucular rezin matriksen kopabilir ve yüzeyde boşluklar oluşturarak yüzey pürüzlüğünün artmasına ve sonucunda da renklenmeye yol açabilir ${ }^{33}$. Ertaş ve arkadaşları $^{24}$ nanohibrit kompozitlerin mikrohibrit kompozitlerden daha az renk değişimi gösterdiğini belirtmişlerdir. Bu çalışmada Quixfil grubunun X-tra fil grubuna göre renk değişim miktarının fazla olmasını, Quixfil' in doldurucu partikül boyutunun büyük olması etkilemiş olabilir.

\section{SONUÇ}

Diyetle alınan içeceğin tipi ve $\mathrm{pH}^{\prime}$ nın rezin kompozitlerin renk stabilitesine ve yüzey pürüzlülüğüne etkili olduğu, kırmızı şarabın materyalin renk değişikliğinin ve yüzey pürüzlülüğünün artmasında en etkili içecek olduğu, renk değişikliklerinin bekletme süresinden etkilendiği saptanmıştır.

\section{KAYNAKLAR}

1. Hickey D, Sharif O, Janjua F, Brunton PA. Bulk dentine replacement versus incrementally placed resin composite: A randomised controlled clinical trial. J Dent 2016;46:18-22.

2. Altun C. Kompozit Dolgu Materyallerinde Son Gelişmeler. Gülhane Tıp Dergisi 2005;47 (1):77- 82

3. Jackson RD, Morgan M. The New Posterior Resins and a Simplified Placement technique. JADA 2000; 131:375-83.
4. Dayangaç, B.: Kompozit Rezin Restorasyonlar, Ankara-2000, Güneş Kitabevi LTD. Şti. Say:1-20, 74-84

5. Hosoya $Y$, Shiraishi T, Odatsu T, Nagafuji J, Kotaku M, Miyazaki M, Powers JM. Effects of polishing on surface roughness, gloss, and color of resin composites. J Oral Sci 2011;53:283-91.

6. Gül P, Akgül N. Farklı kompozit rezinlerin translüsensi ve maskeleme özelliklerinin karşılaştırılması. Atatürk Üniv. Diş Hek. Fak. Derg 2013;21:30-6

7. Ozel E, Korkmaz Y, Attar N, Karabulut E. Effect of one-step polishing systems on surface roughness of different flowable restorative materials. Dent Mater J 2008;27:755- 64.

8. Korkmaz Y, Ozel E, Attar N, Aksoy G. The influence of one-step polishing systems on the surface roughness and microhardness of nanocomposites. Oper Dent 2008;33:44-50.

9. Watanabe T, Miyazaki M, Takamizawa T, Kurokawa $\mathrm{H}$, Rikuta A, Ando S. Influence of polishing duration on surface roughness of resin composites. J Oral Sci 2005;47:21-5.

10. Jung M, Sehr K, Klimek J. Surface texture of four nanofilled an done hybrid composite after finishing. Oper Dent 2007;32:45-52.

11. Biçer CÖ, Attar N, Korkmaz Y. Farklı polisaj tekniklerinin estetik kompozitlerin yüzey pürüzlülüğü üzerine etkileri. A.Ü. Diş Hek. Fak. Derg 2011;38:71-6.

12. Asmussen E, Hansen EK. Surface discoloration of restorative resins in relation to surface softening and oral hygiene. Scandinavian J Dent Res 1986;94:174-7.

13. Bagheri $R$, Burrow MF, Tyas $M$. Influence of foodsimulating solutions and surface finish on susceptibility to staining of aesthetic restorative materials. J Dent 2005;33:389-98

14. Stephen W. Review of the CIE System of Colorimetry and Its Use in Dentistry. J Esthet Restor Dent 2003;15:5-12.

15. Gül P, Akgül N. Kompozit materyaller arasındaki renk farklııklarının farklı skalalarla spektrofotometrik olarak karşılaştırılması. Atatürk Üniv. Diş Hek Fak Derg 2013;21:16-23.

16. Delwin TL, Alvin GW. Perceptibility and acceptability of CIELAB color differences in computer-simulated teeth. J Dent 2007;35:593-9.

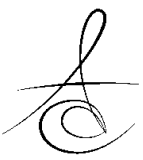


17. Saraç Ş, Saraç D, Yüzbaşıŏ̆lu E. Üç farkı renk skalasının renk farklılıkları yönünden kolorimetrik olarak incelenmesi. Acta Odontol Turcica 2006;23: 85-90

18. Lee YK, Yu B, Lee SH, Cho MS, Lee CY, Lim HN. Shade compatibility of esthetic restorative materials-A review. Dent Mater 2010;26:1119-26.

19. Erkli H, Ersöz E. Farklı fluor jellerin rezin materyallerin yüzey pürüzlülüğü üzerine etkisinin karşıllaştırılması. Acta Odontol Turcica 2012;29:7985.

20. Bani M, Öztaş N. Cam iyonomer içerikli farklı restoratif materyallerin yüzey pürüzlülüklerinin değerlendirilmesi. Acta Odontologica Turcica 2013;30:13-7.

21. Türkün LŞ, Türkün $M$. Effect of bleaching and repolishing procedures on coffee and tea stain removal. J Esth Res Dent 2004;16:290-301

22. Duymuş ZY, Sağsöz NP, Sağsöz Ö, Bayındır F. Seromerlerin farklı solusyonlardaki renk değişimlerinin incelenmesi. Atatürk Üniv Diş Hek Fak Derg 2014;24:81-4.

23. Gül P, Akgül N, Çatakçı AG, Atila A. Ksılıtollü sakız, siyah çay ve beyaz peynirin tükürük $\mathrm{ph}^{\prime}$ sına etkileri. Atatürk Üniv Diş Hek Fak Derg 2011;21: 88-93.

24. Ertaş $E$, Güler AU, Yücel $A C$, Köprülü $H$, Güler E. Color stability of resin composites after immersion in different drinks. Dent Mater J 2006;25:371-6.

25. Fujita M, Kawakami S, Noda M, Sano H. Color change of newly developed esthetic restorative material immersed in food-simulating solutions. Dent Mater J 2006;25:352-9.

26. Köprülü H, Dayangaç B, Gürgan S, Önen A. Farklı posterior kompozitlerin kahve ve çay ile boyanması. A Ü Diş Hek Fak Derg 1992;19:371.

27. Um CM, Ruyter IE. Staining of resin-based veneering materials with coffee and tea. Quint Inter 1991;22:377-86.

28. Poggio C, Dagna A, Chiesa M, Colombo M, Scribante A. Surface roughness of flowable resin composites eroded by acidic and alcoholic drinks. J Conser Dent 2012;15:137-40.

29. Lussi A, Jaeggi T. Erosion-diagnosis and risk factors. Clin Oral Invest 2008;12:5-13.
30. Isabel CAC, Domınguette AAS, Santos SG, Ribeiro JCR, Moysés MR. Surface roughness of a resin composite. RGO - Revista Gaúcha de Odontologia 2016;64:50-5.

31. Iscan Yapar M, Gül P. Farkli içeceklerde bekletilen siloran ve dimetakrilat esasli kompozitlerin renk stabilitelerinin karsilastirilmasi. Acta Odontol Turc 2015;32:51-6.

32. Barutcigil Ç, Harorı OT, Seven N. Bazı geleneksel içeceklerin mikrohibrit kompozit rezinde meydana getirdiği renk değişikliklerinin incelenmesi. Atatürk Üniv Diş Hek Fak Derg 2012;22:114-9.

33. Lu H, Roeder LB, Lei L, Powers JM. Effect of surface roughness on stain resistance of dental resin composites. J Esthet Restor Dent 2005; 17:102-8.

\section{Yazışma Adresi}

Yrd. Doç. Dr. Neslihan Celik, Atatürk Üniversitesi, Diş Hekimliği Fakültesi Restoratif Diş Tedavisi ABD. 25240/Erzurum-TURKEY

TIf: 04422360944

Fax: 04422360945

E mail: neslihancelik@atauni.edu.tr. 